\title{
Synthesis of Complex Nanoparticle Geometries via pH-controlled Overgrowth of Gold Nanorods
}

Varsha Thambi ${ }^{\dagger}$, Ashish Kar ${ }^{\dagger}$, Piue Ghosh ${ }^{\ddagger}$, Diptiranjan Paital†, Abhay Raj Singh Gautam ${ }^{\mathbb{P}}$, and Saumyakanti Khatua* ${ }^{*}$

† Discipline of Chemistry, Indian Institute of Technology Gandhinagar, Gujarat, India

‡ Discipline of Electrical Engineering, Indian Institute of Technology Gandhinagar, Gujarat, India

P Discipline of Material Science and Engineering, Indian Institute of Technology Gandhinagar, Gujarat, India

Email: khatuask@iitgn.ac.in 
1. TEM analysis of gold nanorods:
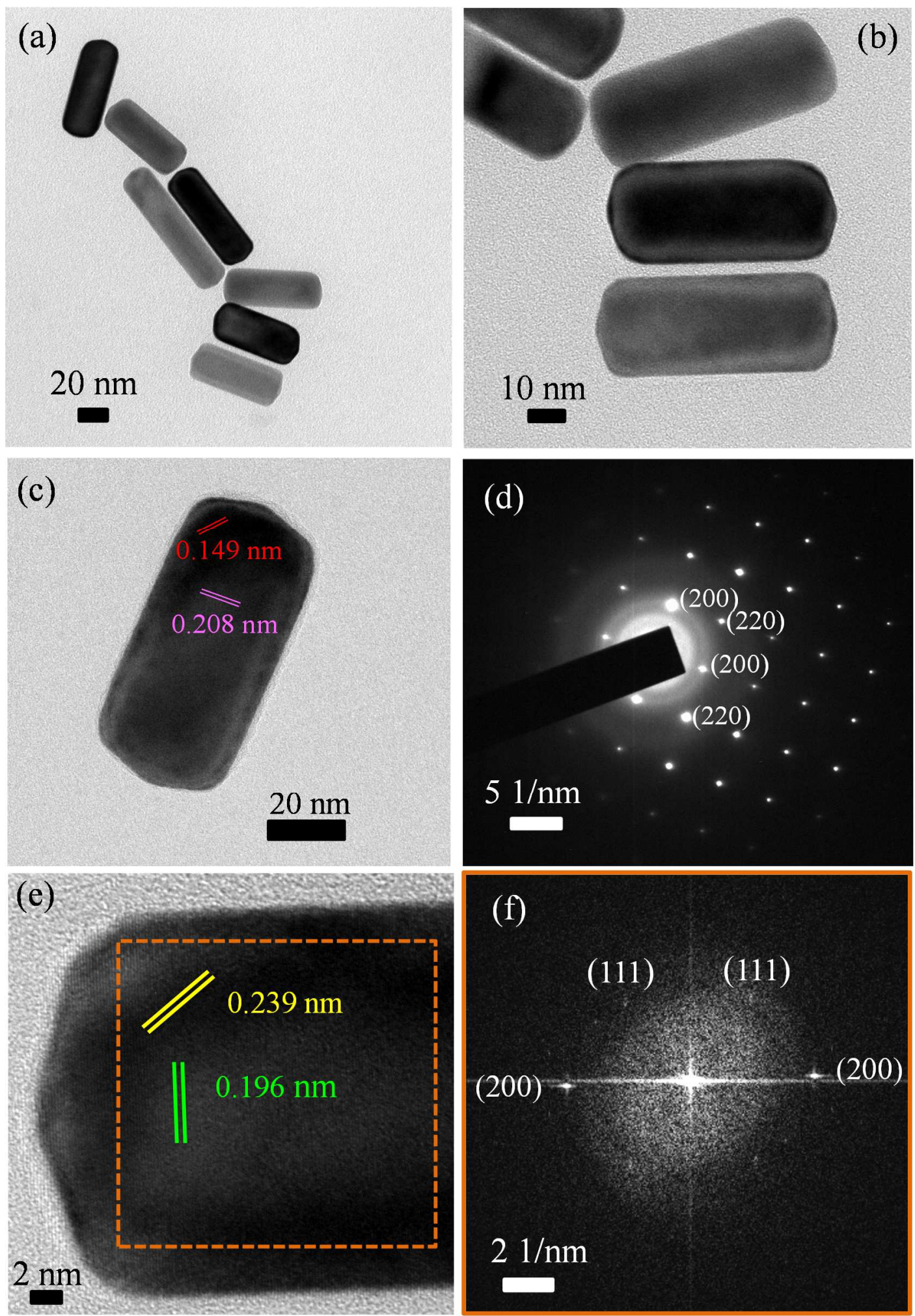

Figure S1: (a-b) Transmission electron microscope image of gold nanorod. (c-d) HRTEM image and the corresponding SAED pattern indicating the presence of $\{100\}$ and $\{110\}$ along [100] zone axis. (e-f) High Resolution Transmission Electron Microscope image and the corresponding FFT image of the selected area (orange box) indicating the orientation of the $\{111\}$ and $\{100\}$ planes in the particle when viewed along [110]. 


\section{TEM analysis of overgrown nanostructures:}

(i) Water Chestnut
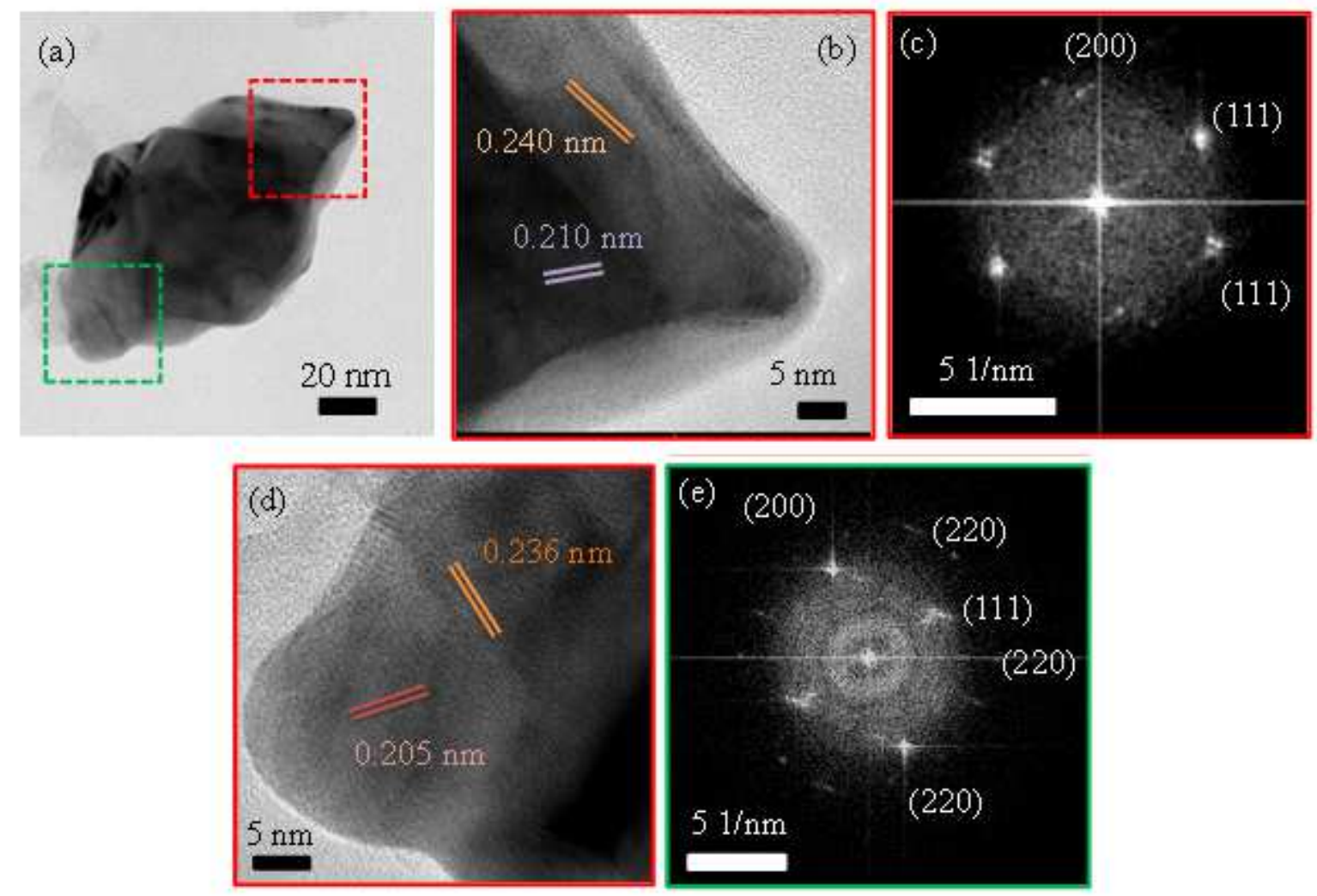

Figure S2(i): (a) TEM image of water chestnut. (b) HRTEM image of the selected red region and its corresponding (c) FFT image (d) HRTEM image of the selected green region and its correspond (e) FFT image.

(ii) Octahedron
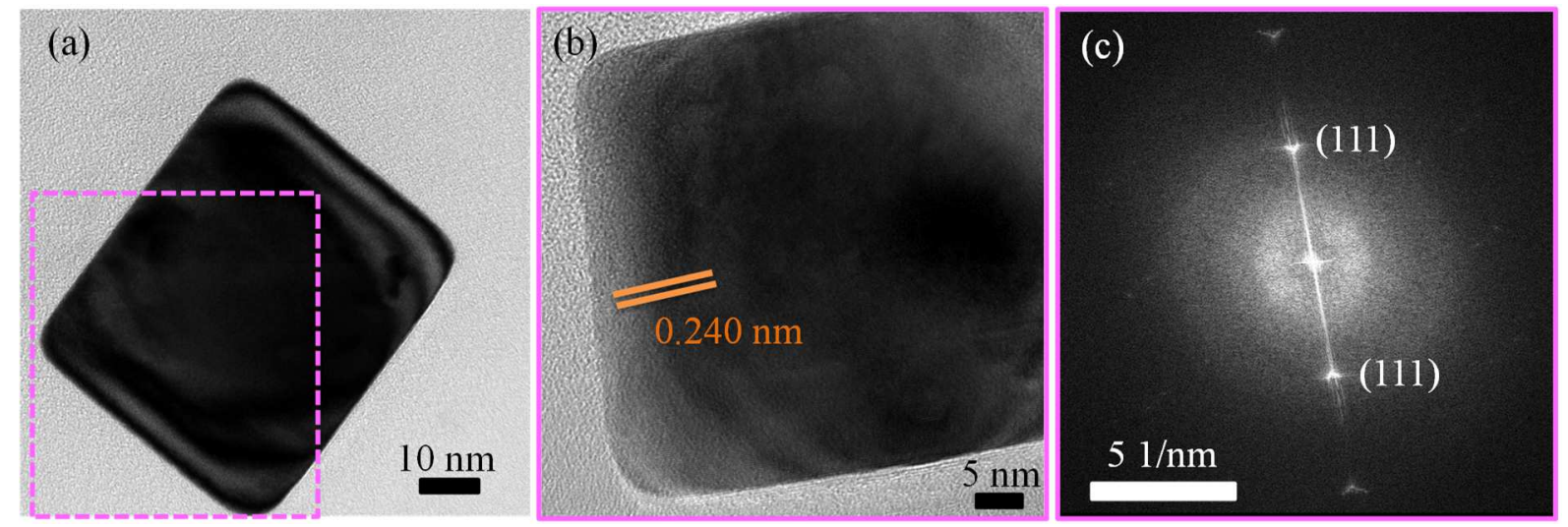

Figure S2(ii): (a) TEM image of octahedron (b) HRTEM image of the octahedron and its corresponding FFT image (c) indicating the orientation of the $\{111\}$ planes in the particle. 
(iii) Dog bone
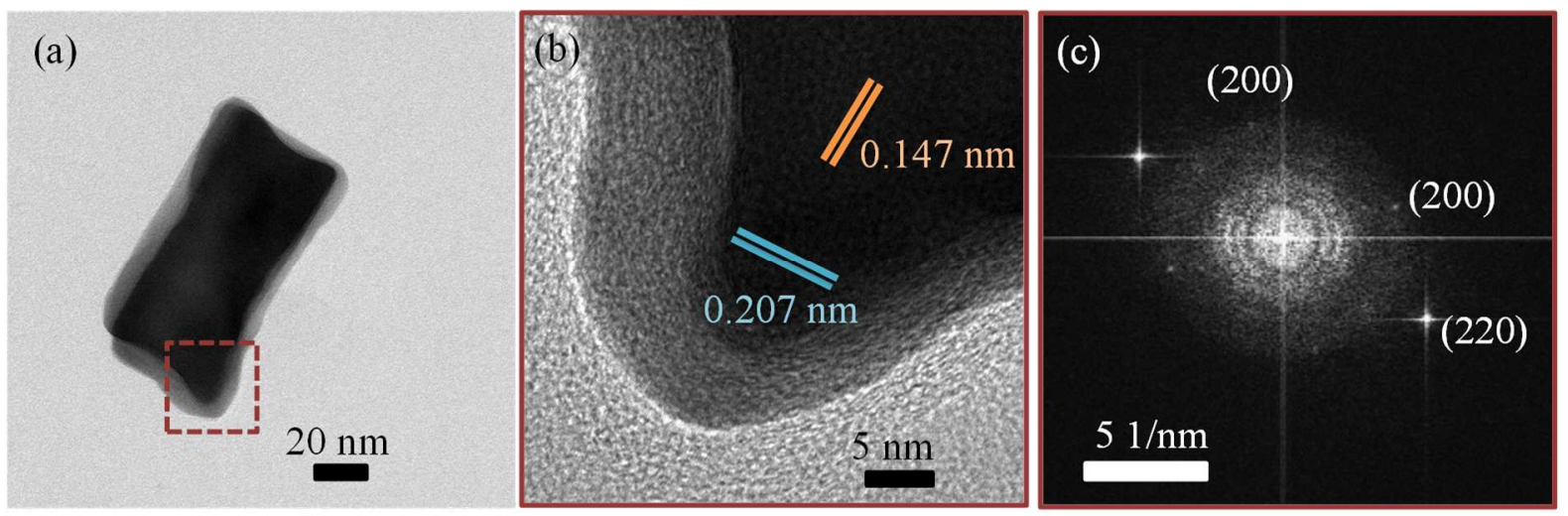

Figure S2(iii): (a) TEM image of dog bone (b) HRTEM image of the selected blue region of dog bone and its corresponding FFT image (c) indicating the orientation of the $\{200\}$ and (220) in the particle when viewed along [100] direction.

(iv) Nanorod
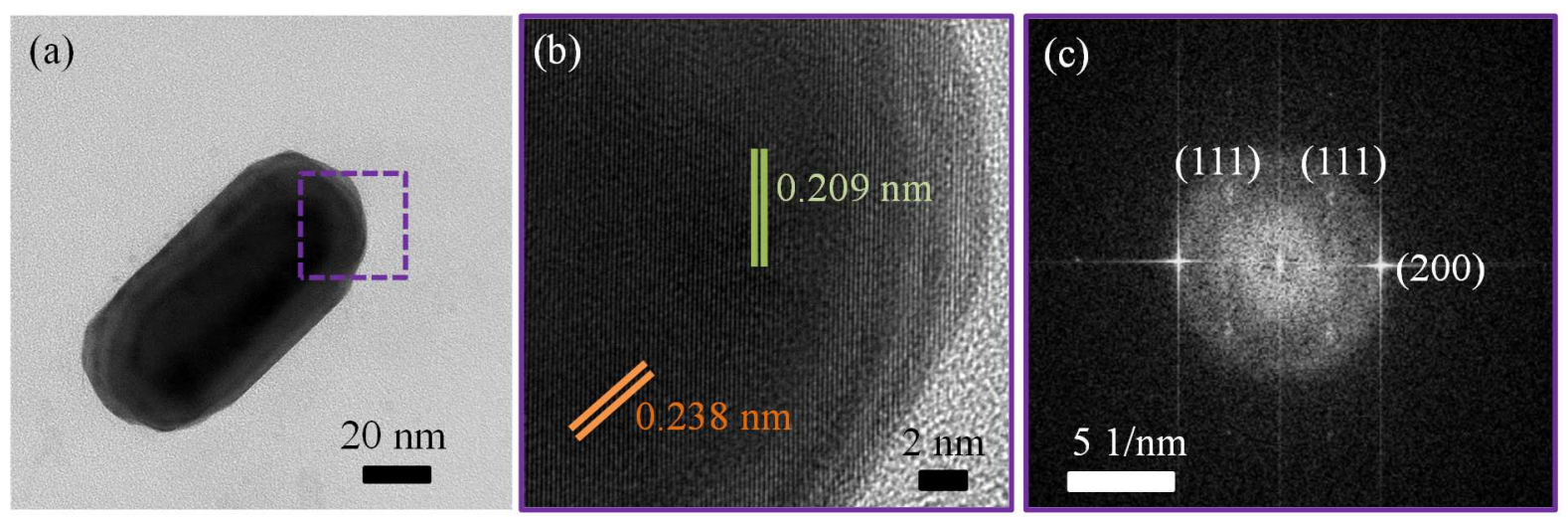

Figure S2(iv): (a) TEM image of overgrown nanorod (b) HRTEM image of the selected purple region of overgrown nanorod and its corresponding FFT image (c) indicating the orientation of $\{200\}$ and (111) planes with viewed along [110] direction. 


\section{ICP-OES studies on nanorod growth}

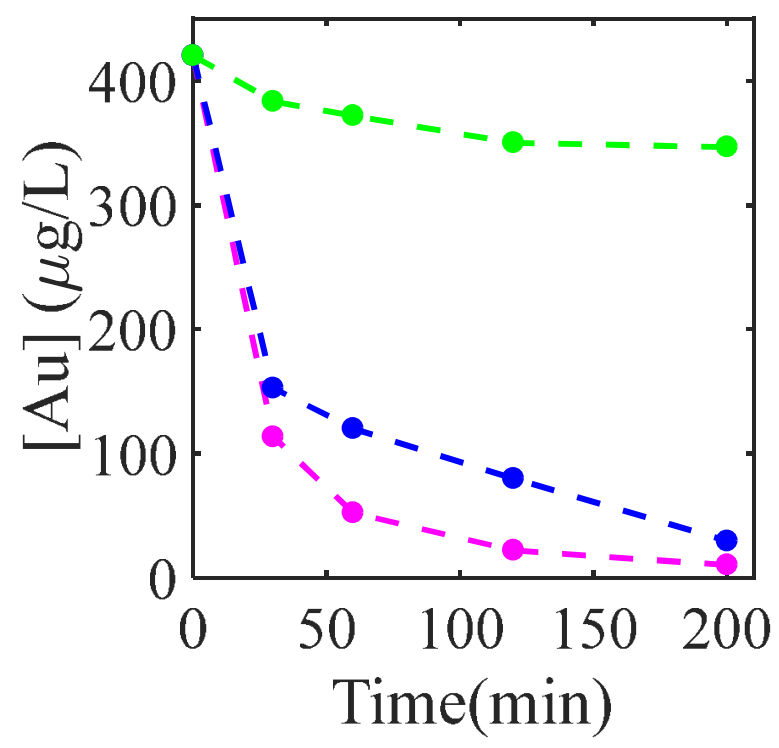

Figure S3: shows the concentrations of gold ions remaining in solution as function of time at pH 8.0 (magenta), pH 4.0 (blue), and pH 2.0 (green) calculated through ICP-OES. Reaction was stopped at $30 \mathrm{~min}, 60 \mathrm{~min}, 120 \mathrm{~min}$ and 200min by centrifugation.

\section{Redox potential of hydroquinone at different $\mathrm{pH}$}

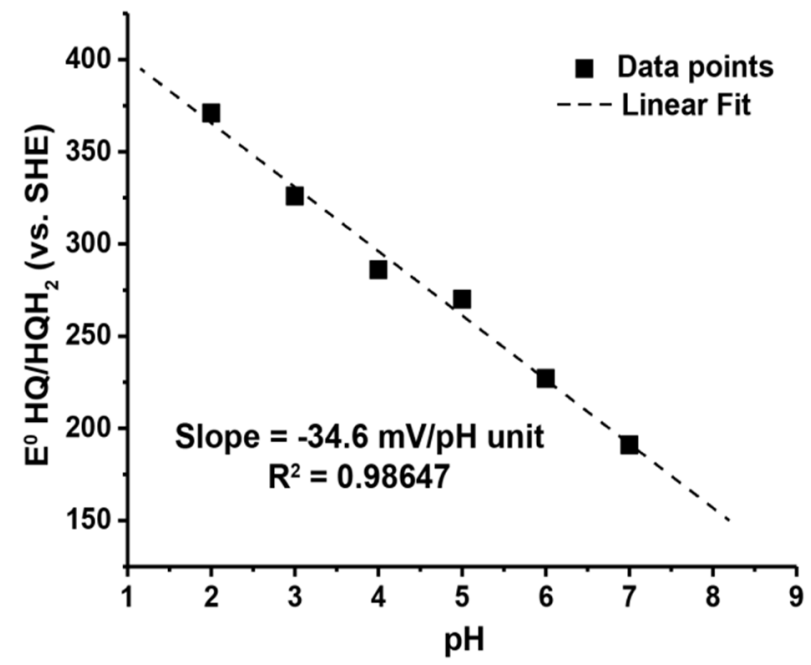

Figure S4: Reduction potential of hydroquinone at different solution $\mathrm{pH}$. 

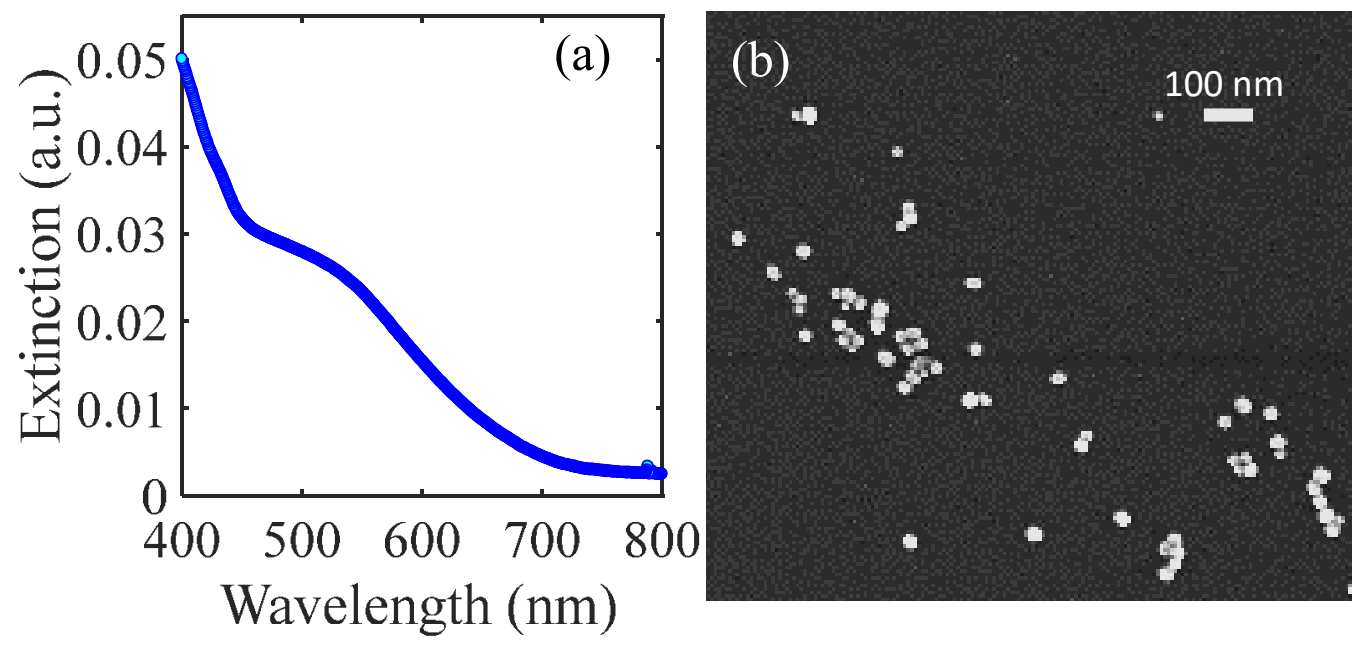

Figure S5: (a) Extinction spectra of the growth solution at $\mathrm{pH} 8$ and the corresponding SEM image (b) of the solution indicating the formation of small Au nanoparticles at $\mathrm{pH} 8$ in the absence of gold nanorod seed.

6. Ag content in overgrown nanoparticles via ICP-OES

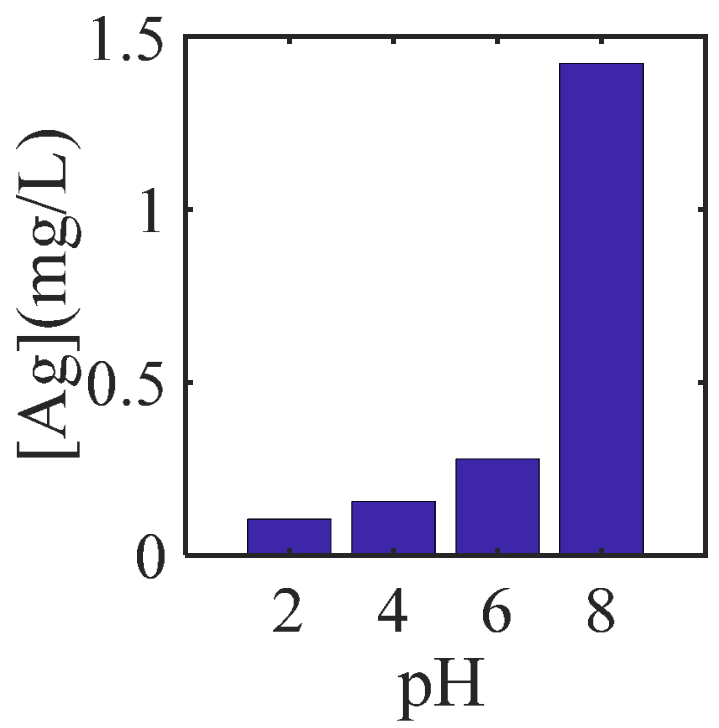

Figure S6: shows the increase in the concentration of Ag on the overgrown nanoparticle at different pH obtained through ICP-OES. 

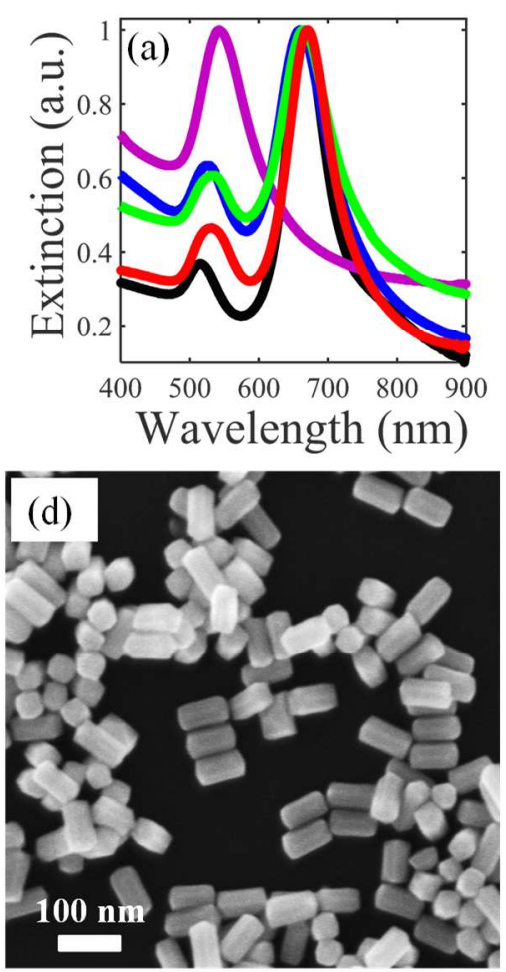
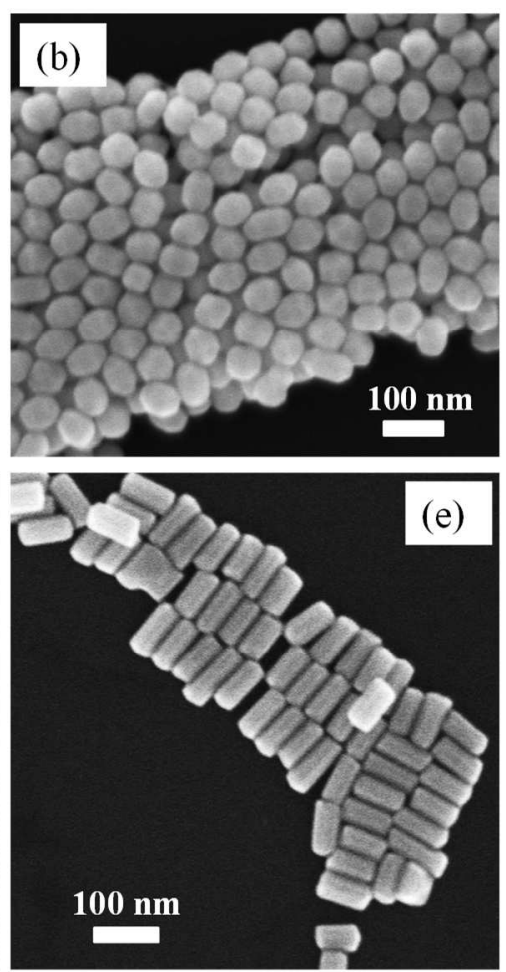
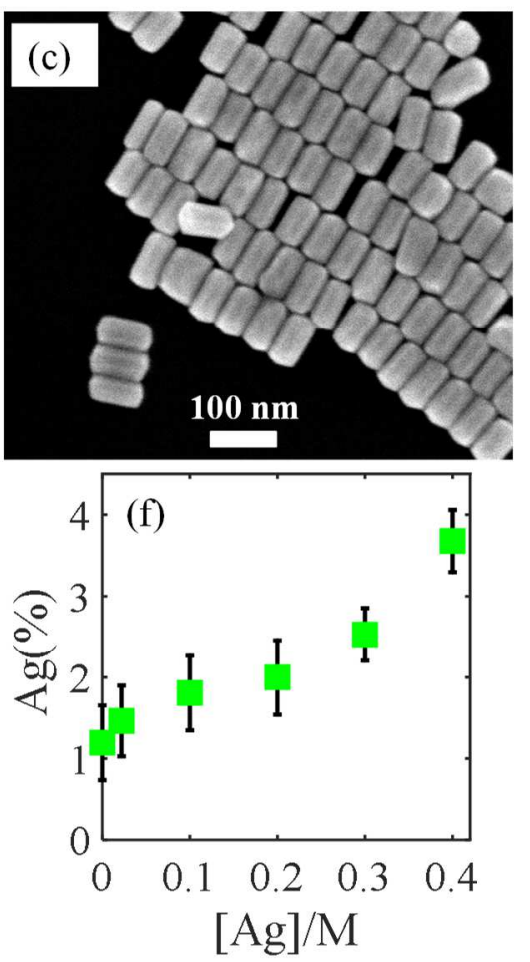

Figure S7: (a) Extinction spectra of overgrown nanorods at low $\mathrm{pH}(\mathrm{pH}$ 2) where concentration of silver nitrate was changed. SEM images of (b) [Ag]: O(pink) (c) [Ag]: 0.1 $M$ (blue) (d) [Ag]: $0.2 \mathrm{M}$ (green) and (e) $0.4 \mathrm{M}$ (red). (f) Shows the increase in the atomic percentage of $\mathrm{Ag}(\%)$ with increase in the concentration of $\mathrm{Ag}$ in the growth solution. 

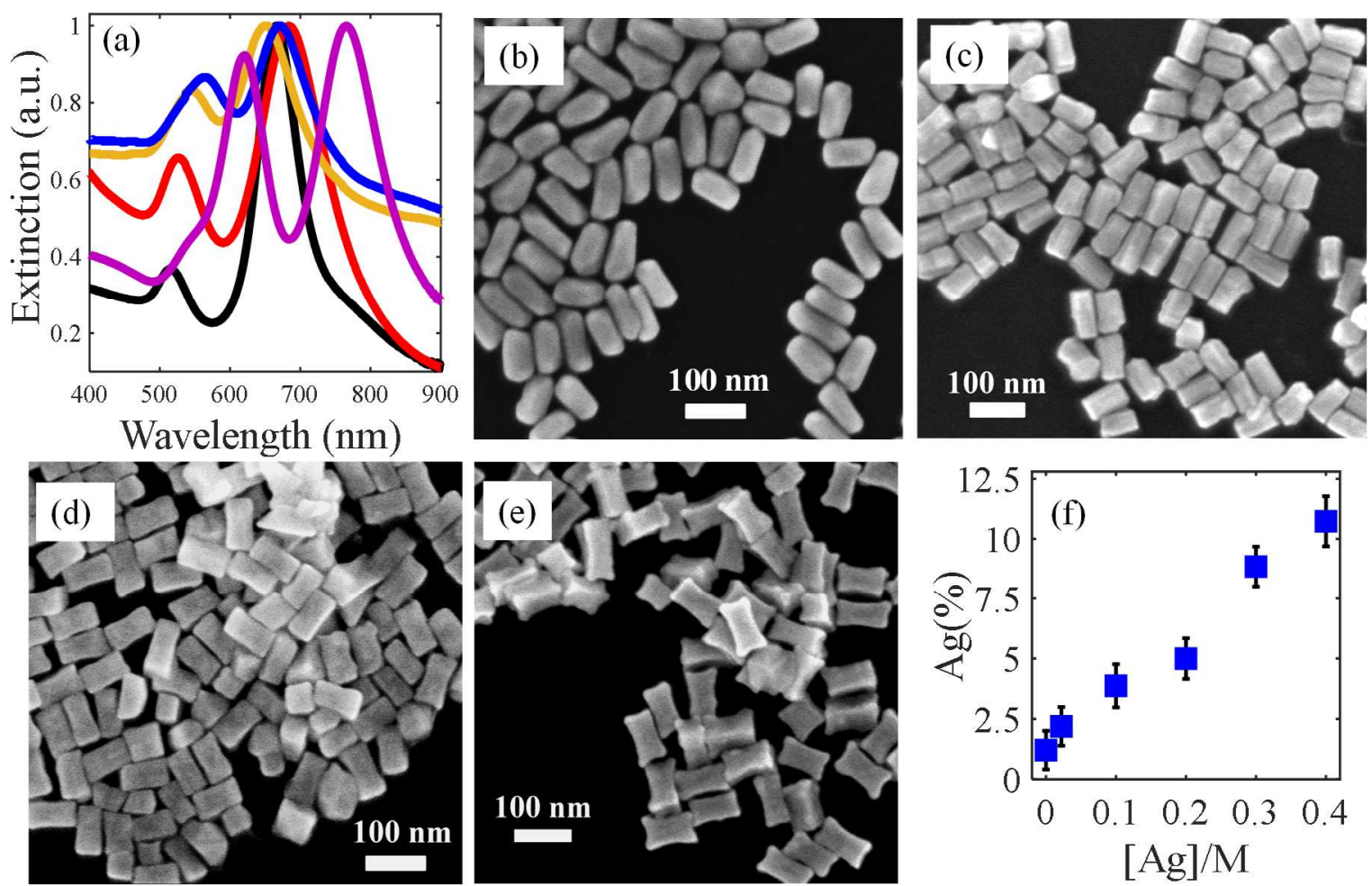

Figure S8: (a) Extinction spectra of gold nanoparticles grown at pH 4 by sequentially increasing the concentration of silver nitrate. SEM images of nanoparticles obtained at different silver nitrate concentration (b) $[\mathrm{Ag}]=0$ (red) (c) $[\mathrm{Ag}]=0.12 \mathrm{M}$ (yellow) (d) [Ag]: $0.2 \mathrm{M}$ (blue) and (e) [Ag]: $0.4 \mathrm{M}$ (pink). (f) Shows the increase in the atomic ratio of $\mathrm{Ag} / \mathrm{Au}$ with increase in the concentration of $\mathrm{Ag}$ in the growth solution. 

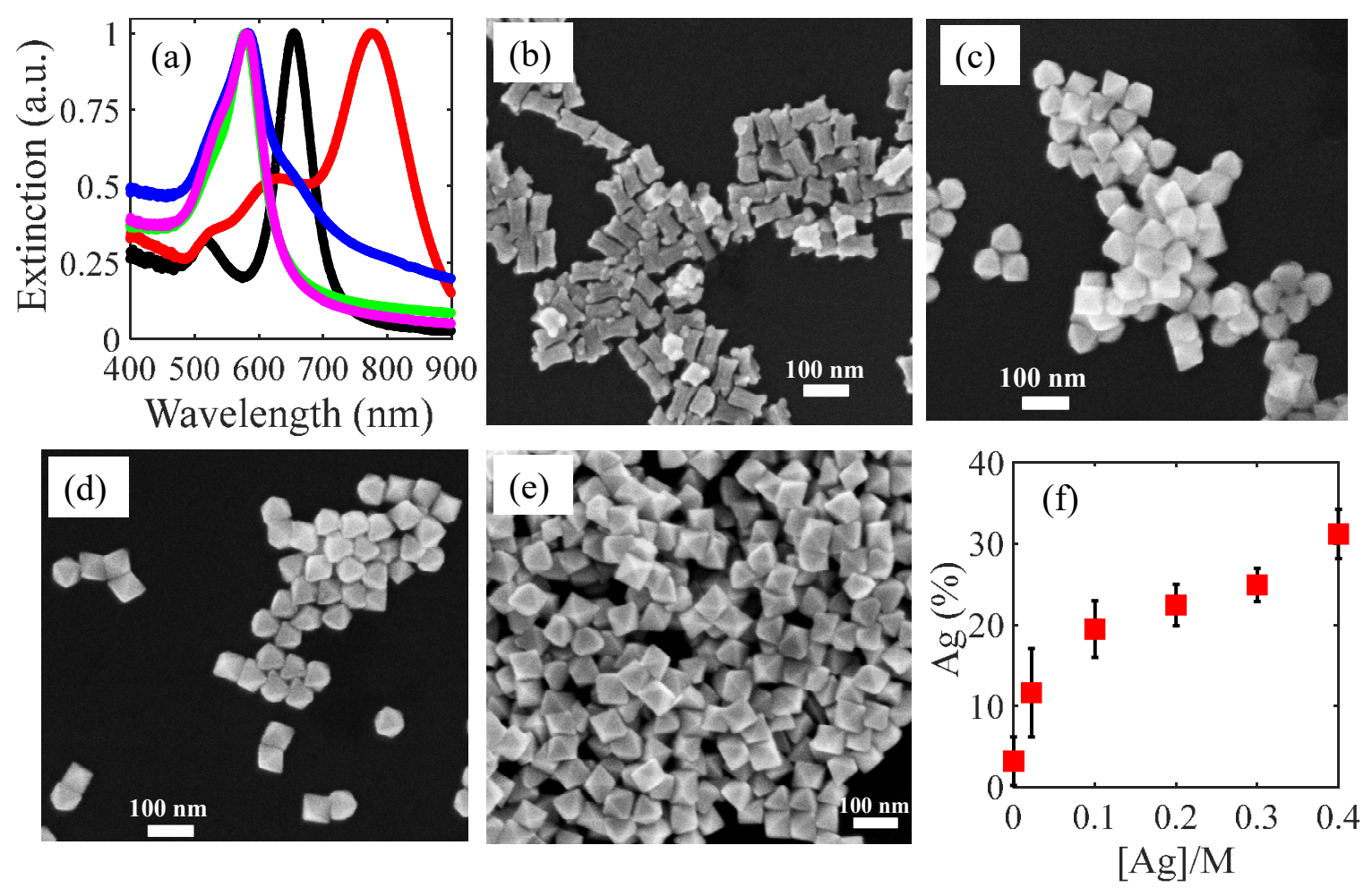

Figure S9: (a) Extinction spectra of gold nanoparticles grown at pH 6 by sequentially increasing the concentration of silver nitrate. SEM images of nanoparticles obtained at different silver nitrate concentration (b) $[\mathrm{Ag}]=0$ (red) (c) $[\mathrm{Ag}]=0.1 \mathrm{M}$ (green) (d) $[\mathrm{Ag}]$ : $0.2 \mathrm{M}$ (blue) and (e) [Ag]: $0.4 \mathrm{M}$ (magenta). (f) Shows the increase in the atomic ratio of $\mathrm{Ag} / \mathrm{Au}$ with increase in the concentration of $\mathrm{Ag}$ in the growth solution. 

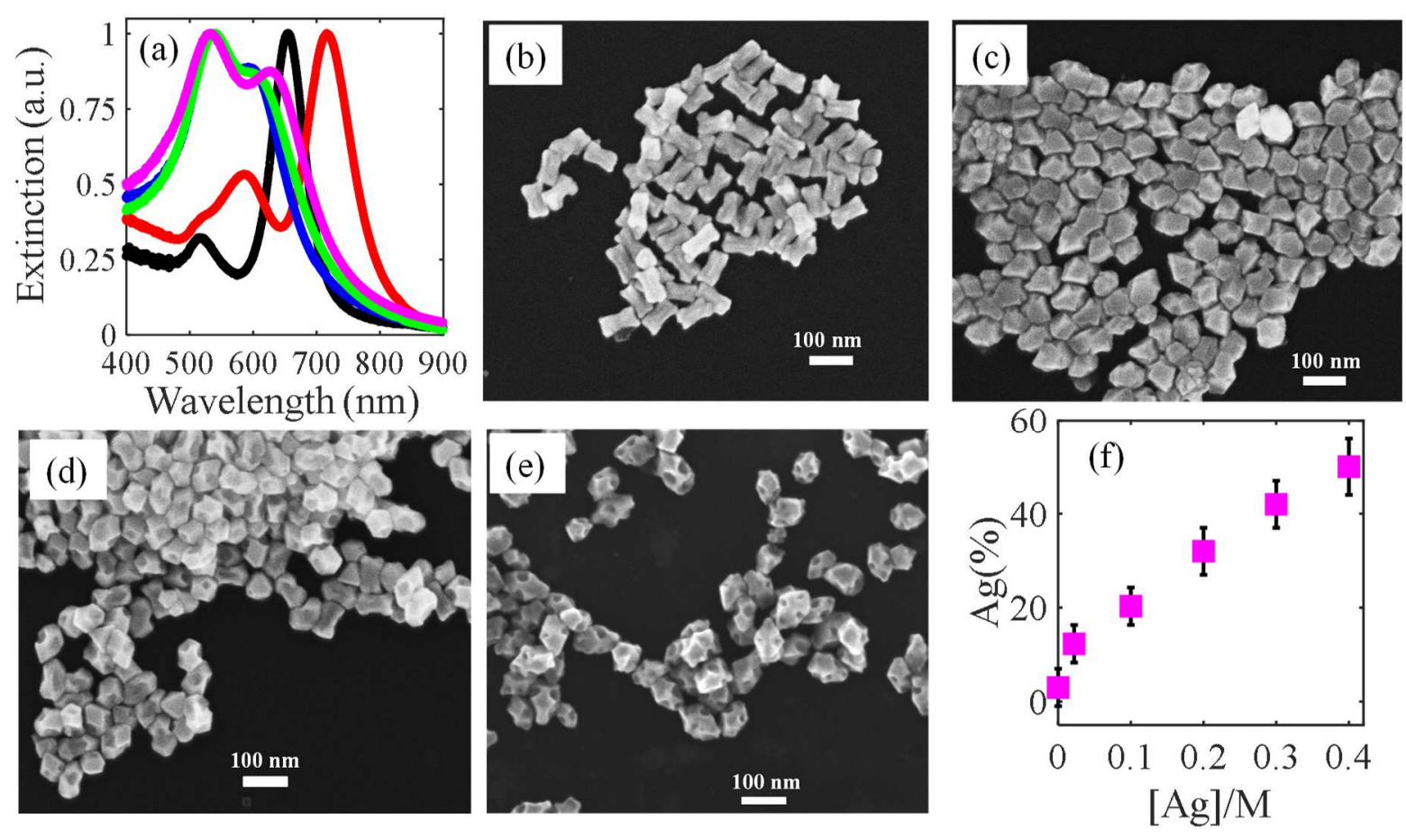

Figure S10: (a) Extinction spectra of gold nanoparticles grown at $\mathrm{pH} 8$ by sequentially increasing the concentration of silver nitrate. SEM images of nanoparticles obtained at different silver nitrate concentration (b) $[\mathrm{Ag}]=0$ (red) (c) $[\mathrm{Ag}]=0.1 \mathrm{M}$ (blue) (d) $[\mathrm{Ag}]: 0.2$ $M$ (green) and (e) [Ag]: $0.4 \mathrm{M}$ (magenta). (f) Shows the increase in the atomic ratio of $\mathrm{Ag} / \mathrm{Au}$ with increase in the concentration of $\mathrm{Ag}$ in the growth solution. 


\section{Effect of HBr on gold nanorod overgrowth}
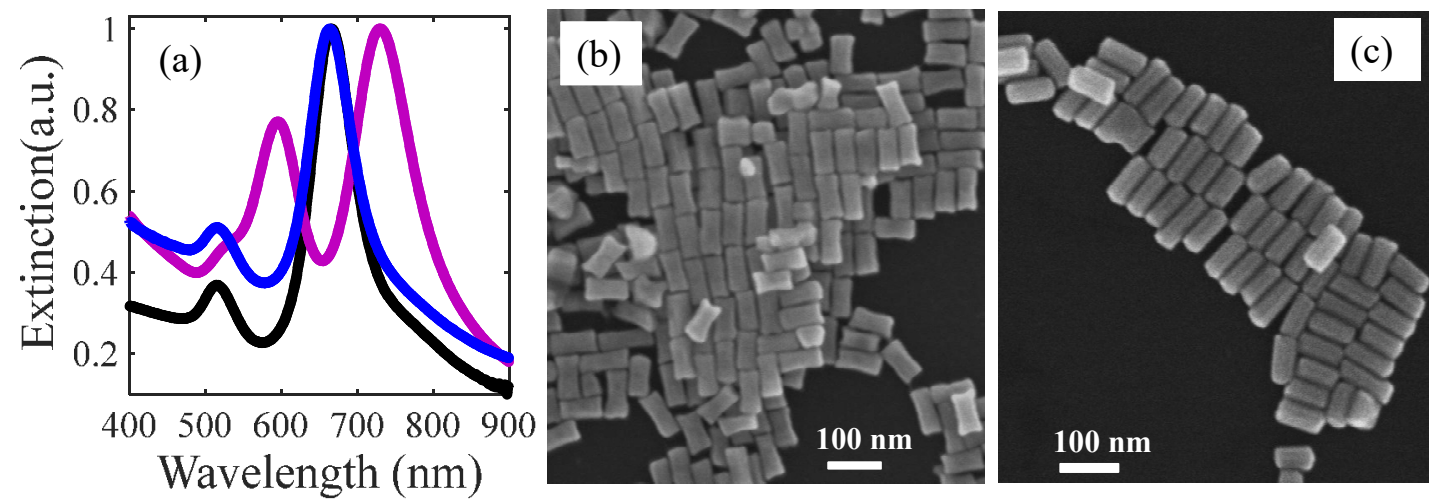

Figure S11: (a) Extinction spectra of AuNRs (black) obtained by overgrowth at two different $\mathrm{pH}$ of $\mathrm{pH} 4$ (pink) and $\mathrm{pH} 2$ (blue) where $\mathrm{pH}$ of the growth solution was varied using $\mathrm{HBr}$ solution. SEM images of the nanostructures dog bone and nanorod obtained at (b) $\mathrm{pH} 4$ and (c) $\mathrm{pH} 2$ respectively. 
Table S1: Summary of overgrown nanoparticles' shapes obtained at different $p H$, their TSPR and LSPR wavelengths, and their dimension along with the average length and width of the nanoparticles measured for over 100 particles.

\begin{tabular}{|c|c|c|c|c|c|}
\hline$p H$ & Shape & $\begin{array}{c}T S P R \\
(\mathrm{~nm})\end{array}$ & $\begin{array}{c}\text { LSPR } \\
(\mathrm{nm})\end{array}$ & $\begin{array}{c}\text { Length } \\
(\mathrm{nm})\end{array}$ & $\begin{array}{c}\text { Width } \\
(\mathrm{nm})\end{array}$ \\
\hline 8 & $\begin{array}{c}\text { Water } \\
\text { Chestnut }\end{array}$ & 532.5 & 633.5 & $91( \pm 12)$ & $66( \pm 7)$ \\
\hline 6 & Octahedron & 555.5 & 577 & $72( \pm 9)$ & $62( \pm 7)$ \\
\hline 4 & Dog-bone & 537.5 & 761 & $93( \pm 9)$ & $35( \pm 2)$ \\
\hline 2 & Nanorod & 532 & 671 & $84( \pm 7)$ & $39( \pm 3)$ \\
\hline
\end{tabular}

Table S2: Summary of different shapes obtained at different $p H$ condition and their corresponding TSPR and LSPR along with the average length and width of the nanoparticles measured for over 100 particles in the absence of silver nitrate.

\begin{tabular}{|c|c|c|c|c|c|}
\hline$p H$ & Shape & $\begin{array}{c}\text { TSPR } \\
(\mathrm{nm})\end{array}$ & $\begin{array}{c}\text { LSPR } \\
(\mathrm{nm})\end{array}$ & $\begin{array}{c}\text { Length } \\
(\mathrm{nm})\end{array}$ & $\begin{array}{c}\text { Width } \\
(\mathrm{nm})\end{array}$ \\
\hline 8 & Dog bone & 523.5 & 776 & $78( \pm 6)$ & $38( \pm 3)$ \\
\hline 6 & Dog bone & 515 & 717.5 & $76( \pm 5)$ & $35( \pm 3)$ \\
\hline 4 & Nanorod & 518 & 640 & $100( \pm 10)$ & $44( \pm 5)$ \\
\hline 2 & Icosahedron & 542 & - & $74( \pm 8)$ & $50( \pm 5)$ \\
\hline
\end{tabular}

Table S3: Summary of different shapes obtained at pH 2 and their corresponding TSPR and LSPR along with the average length and width of the nanoparticles measured for over 100 particles.

\begin{tabular}{|c|c|c|c|c|c|}
\hline $\begin{array}{c}{[\mathrm{Ag}] \text { at } \mathrm{pH} 2} \\
(\mathrm{M})\end{array}$ & Shape & $\begin{array}{c}\text { TSPR } \\
(\mathrm{nm})\end{array}$ & $\begin{array}{c}\text { LSPR } \\
(\mathrm{nm})\end{array}$ & $\begin{array}{c}\text { Length } \\
(\mathrm{nm})\end{array}$ & $\begin{array}{c}\text { Width } \\
(\mathrm{nm})\end{array}$ \\
\hline 0 & Icosahedron & 542.5 & - & $74( \pm 8)$ & $50( \pm 5)$ \\
\hline 0.1 & Nanorod & 525 & 660 & $87( \pm 14)$ & $39( \pm 3)$ \\
\hline 0.2 & Nanorod & 532.5 & 665 & $86( \pm 9)$ & $40( \pm 5)$ \\
\hline 0.4 & Nanorod & 528 & 670 & $84( \pm 7)$ & $39( \pm 3)$ \\
\hline
\end{tabular}


Table S4: Summary of different shapes obtained at pH 4 and their corresponding TSPR and LSPR along with the average length and width of the nanoparticles measured for over 100 particles.

\begin{tabular}{|c|c|c|c|c|c|}
\hline $\begin{array}{c}{[\mathrm{Ag}] \text { at } \mathrm{pH} 4} \\
(\mathrm{M})\end{array}$ & Shape & $\begin{array}{c}\text { TSPR } \\
(\mathrm{nm})\end{array}$ & $\begin{array}{c}\text { LSPR } \\
(\mathrm{nm})\end{array}$ & $\begin{array}{c}\text { Length } \\
(\mathrm{nm})\end{array}$ & $\begin{array}{c}\text { Width } \\
(\mathrm{nm})\end{array}$ \\
\hline 0 & Nanorod & 526.5 & 683.5 & $100( \pm 10)$ & $44( \pm 5)$ \\
\hline 0.1 & Nanobar & 543 & 650.5 & $80( \pm 10)$ & $44( \pm 5)$ \\
\hline 0.2 & Nanobar & 563 & 670.5 & $76( \pm 8)$ & $34( \pm 5)$ \\
\hline 0.4 & Dog Bone & 537.5 & 765.5 & $93( \pm 9)$ & $35( \pm 2)$ \\
\hline
\end{tabular}

Table S5: Summary of different shapes obtained at pH 6 and their corresponding TSPR and LSPR along with the average length and width of the nanoparticles measured for over 100 particles.

\begin{tabular}{|c|c|c|c|c|c|}
\hline $\begin{array}{c}{[\mathrm{Ag}] \text { at pH 6 }} \\
(\mathrm{M})\end{array}$ & Shape & $\begin{array}{c}\text { TSPR } \\
(\mathrm{nm})\end{array}$ & $\begin{array}{c}\text { LSPR } \\
(\mathrm{nm})\end{array}$ & $\begin{array}{c}\text { Length } \\
(\mathrm{nm})\end{array}$ & $\begin{array}{c}\text { Width } \\
(\mathrm{nm})\end{array}$ \\
\hline 0 & Dog bone & 523.5 & 777 & $92( \pm 7)$ & $35( \pm 3)$ \\
\hline 0.1 & Octahedron & 529 & 579 & $80( \pm 5)$ & $68( \pm 6)$ \\
\hline 0.2 & Octahedron & 528.5 & 582.5 & $80( \pm 6)$ & $71( \pm 7)$ \\
\hline 0.4 & Octahedron & 534 & 582.5 & $72( \pm 9)$ & $62( \pm 7)$ \\
\hline
\end{tabular}

Table S6: Summary of different shapes obtained at pH 8 and their corresponding TSPR and LSPR along with the average length and width of the nanoparticles measured for over 100 particles.

\begin{tabular}{|c|c|c|c|c|c|}
\hline$[\mathrm{Ag}]$ at $\mathrm{pH} 8$ & Shape & $\begin{array}{c}\text { TSPR } \\
(\mathrm{nm})\end{array}$ & $\begin{array}{c}\text { LSPR } \\
(\mathrm{nm})\end{array}$ & $\begin{array}{c}\text { Length } \\
(\mathrm{nm})\end{array}$ & $\begin{array}{c}\text { Width } \\
(\mathrm{nm})\end{array}$ \\
\hline 0 & Dog bone & 518 & 717 & $90( \pm 8)$ & $38( \pm 3)$ \\
\hline 0.1 & Water-Chestnut & 538.5 & 597.5 & $80( \pm 11)$ & $70( \pm 5)$ \\
\hline 0.2 & Water-Chestnut & 543 & 605 & $101( \pm 12)$ & $68( \pm 7)$ \\
\hline 0.4 & Water-Chestnut & 533 & 629.5 & $91( \pm 12)$ & $66( \pm 7)$ \\
\hline
\end{tabular}

